\title{
Movement control exercise versus general exercise to reduce disability in patients with low back pain and movement control impairment. A randomised controlled trial
}

\author{
Jeannette Saner ${ }^{1 *}$, Jan Kool ${ }^{1}$, Rob A de Bie ${ }^{2}$, Judith M Sieben ${ }^{3}$ and Hannu Luomajoki ${ }^{1}$
}

\begin{abstract}
Background: Non-specific low back pain (NSLBP) in subacute and chronic stages can be treated effectively with exercise therapy. Research guidelines recommend evaluating different treatments in defined subgroups of patients with NSLBP. A subgroup of patients with movement control impairment $(\mathrm{MCl})$ improved significantly on patient specific function and disability in a previous case series after movement control exercises.

Methods/Design: In a randomised controlled trial (RCT) we will compare the effectiveness of movement control and general exercise in patients with $\mathrm{MCl}$. 106 participants aged 18 - 75 will be recruited in 5 outpatient hospital departments and 7 private practices.

Patients randomly assigned to the movement control exercise group will be instructed to perform exercises according to their $\mathrm{MCl}$. The general exercise group will follow an exercise protocol aimed at improving endurance and flexibility. Patients in both groups will receive 9 - 18 treatments and will be instructed to do additional exercises at home.

The primary outcome is the level of disability assessed using the patient specific functional scale (PSFS) which links the perceived pain to functional situations and is measured before treatment and at 6 and 12 months follow-up. Secondary outcomes concern low back pain related disability (Roland Morris questionnaire, RMQ), graded chronic pain scale (GCPS), range of motion and tactile acuity.

Discussion: To our knowledge this study will be the first to compare two exercise programs for a specific subgroup of patients with NSLBP and MCI. Results of this study will provide insight into the effectiveness of movement control exercise and contribute to our understanding of the mechanisms behind $\mathrm{MCl}$ and its relation to NSLBP.

Trial registration: Current Controlled Trials ISRCTN80064281
\end{abstract}

\section{Background}

Low Back Pain (LBP) is one of the major concerns of current health care [1-5]. Only 10\% of LBP cases can be attributed to specific disorders like nerve root compression, vertebral fracture, tumour, infection, inflammatory diseases, spondylolisthesis or spinal stenosis. Consequently, NSLBP, in which the cause of symptoms is

\footnotetext{
* Correspondence: jeannette.saner@zhaw.ch

${ }^{1}$ Institute of Physiotherapy, School of Health Professions, Zurich University of Applied Sciences, Technikumstrasse 71, Postfach, CH - 8401 Winterthur, Switzerland

Full list of author information is available at the end of the article
}

unknown, is diagnosed in about $90 \%$ of all patients and is a health problem of high economic importance [6].

Patients with NSLBP present diverse clinical findings, courses of disease and prognoses. They therefore make up a heterogeneous group of patients, which may explain why treatment effects in numerous studies looking at specific physiotherapy treatments in the NSLBP group are often discouraging. Identifying defined subgroups of patients within the NSLBP population has been a major focus in recent research [7-12]. Current European guidelines encourage outcome studies in

\section{C) Biomed Central}


subgroups of patients with a shared diagnostic pattern or prognosis that might benefit from specific treatments [1]. This research agenda is expected to reveal further evidence for the effect of treatments designed for specific subgroups [13]. Of 767 RCTs about the effect of conservative treatment on chronic LBP performed and published between 1982 and 2008, 68 publications examined manual or exercise therapy, of which five studies had an additional subclassification and matched treatments [14].

There is no evidence for the effectiveness of exercise in patients with acute LBP of a less than 6 week duration [1,15-17], but exercise therapy is effective in chronic and subacute LBP [16]. There is evidence that home exercise may be effective in decreasing pain and disability, but results have shown no significant difference between exercise types on work disability $[1,18]$. There is moderate evidence suggesting that exercise therapy may prevent recurrences of LBP, but there is no evidence for a difference in effect between types of exercise [19]. Individually designed exercise programs are recommended [17] but the question remains as to which types of exercise are effective for which subgroups of patients.

Within the framework of a new NSLBP classification system developed by O'Sullivan, one of the subgroups of patients that can be distinguished contains those suffering from MCI [11]. In a first step, this classification of NSLBP distinguishes between patients with nonmechanical disorders, and patients with mechanical disorders. Whereas in patients with non-mechanical NSLBP, psychosocial factors, fear and catastrophising play central roles, pain in relation to posture and movement is predominant in patients with mechanical NSLBP. Patients with mechanical NSLBP are further divided into those with movement impairment (MI) and movement control impairment (MCI). Patients with MI may suffer movement restrictions in single or multiple directions. $\mathrm{MCI}$ is defined as a deficit in the control of movements during functional daily activities. The range of the movement is not restricted in the MCI group.

Clinical tests to identify MCI were developed in recent research [11,20-26]. Further evaluation revealed six tests which reliably detect MCI in patients [27]. (Additional files 1) These tests will be used to select patients with MCI for this study. Movement control tests are easy to perform in clinical practice. Tests and clinical presentation allow a further classification of movement control dysfunctions according to direction in extension, flexion, frontal plane and multi-directional MCIs. (Table 1)

Two mechanisms are proposed to explain the impaired movement control behaviour. One relates to conditioning and habituation, which are important factors in motor learning. Patients use postures and movements that are potentially harmful due to maladaptive processes, like avoidance or overuse during the acute pain phase [28]. Another mechanism is non-awareness of the posture's pain provocation. Altered cortical representation of the lumbar spine in the presence of pain may play an important role [29]. Two point discrimination is decreased in patients with NSLBP, indicating changes in cortical representation because of NSLBP [30]. Both mechanisms can either be induced by pain or be the cause of pain.

It is hypothesised that, once movement control is impaired, it results in repetitive mechanical deformation of innervated tissue and leads to increased nociceptive input to the central nervous system and, therefore, pain [31]. All joint capsules, ligaments, tendons and muscles are possible pain sources, especially due to continuous strain or longstanding repetitive movements [31,32]. Repeated misuse of these tissues can also initiate the inflammatory cascade, a further cause of pain [33].

The inter-rater reliability of the clinical classification of NSLBP in MI and MCI is very high; in experts and raters with less experience, $\mathrm{k}=0.85$ and $\mathrm{k}=0.6$ respectively $[34,35]$. The inter- and intra-rater reliability of the previously described 6 active tests performed by the patient

Table 1 Five distinct directional patterns of movement control impairment [72] (personal communication)

\begin{tabular}{llll}
\hline $\begin{array}{l}\text { Direction of movement } \\
\text { control impairment }\end{array}$ & Pain aggravation & Pain relief & Movement control deficit \\
\hline Flexion & $\begin{array}{l}\text { Sustained flexion of lumbar spine, e.g. } \\
\text { when sitting }\end{array}$ & $\begin{array}{l}\text { Extension of lumbar spine, e.g. when } \\
\text { standing and walking }\end{array}$ & $\begin{array}{l}\text { Difficulty controlling lordosis in } \\
\text { sitting and flexed positions }\end{array}$ \\
\hline Active Extension & $\begin{array}{l}\text { Sustained extension of lumbar spine } \\
\text { Passive extension }\end{array}$ & $\begin{array}{l}\text { Flexion of lumbar spine, relaxing in flexed } \\
\text { posture. Breathing exercises }\end{array}$ & $\begin{array}{l}\text { Difficulty flexing when sitting or } \\
\text { breathing with diaphragm }\end{array}$ \\
\hline Frontal pain control & $\begin{array}{l}\text { Extension of lumbar spine, e.g. when } \\
\text { standing or walking slowly }\end{array}$ & Flexion of lumbar spine, e.g. while sitting & Tilting pelvis posteriorly \\
\hline Multidirectional pattern & Multidirectional & Control pelvis and thorax in frontal plain & Maintain symmetric posture \\
\hline
\end{tabular}

Description: Specification of main symptoms and signs to classify the direction of movement control impairment 
was evaluated as good to substantial [27]. Validity of MCI tests is supported by significantly different results in healthy subjects, with 0.75 positive MCI tests $(95 \%$ CI $0.55-0.95$ ) and low back pain patients with 2.21 positive $\mathrm{MCI}$ tests $(95 \% \mathrm{CI} 1.94-2.48$, effect size $\mathrm{d}=1.18)$ [36].

In a preceding prior controlled case series, 38 preselected patients with positive MCI tests were treated with an individualised movement control exercise program and showed improvements in MCI test performance associated with improvements in patient specific functional complaints and disability [37]. The present study will compare movement control training with general exercise in a randomised controlled trial.

MCI exercises are often and falsely referred to as motor control exercises, spinal stabilisation or core stability exercises. While MCI exercises aim to improve function through repetitive normal use, the latter retrain delayed muscle activity first in order to improve control of the spine. Several trials and systematic reviews have evaluated the effect of stabilising exercises with conflicting results [38-42]. A recent randomised placebo-controlled trial with a specific stabilisation program in a population with chronic low back pain found a significant improvement in activity in both the short and long term when measured with a patient specific functional scale (PSFS), and a short term improvement for global impression of recovery and disability [43]. However, they did not subgroup the patients and the effects were not beyond the smallest minimal meaningful clinical change.

The general exercise treatment is based on treatments used in previous studies. Exercises were developed to improve endurance, strength and flexibility of the spinal tissues [44]. Experimental studies have shown that these exercises involve many global and local muscles and improve the stability of the spine [45,46]. In an RCT of patients with subacute and chronic NSLBP, a course of only general exercise was compared with a combination of general exercise and stabilisation exercise. Immediately after treatment, disability was significantly lower in the general exercise group. No differences were found in other outcomes or at follow-up time points [47].

Psychosocial factors have an important impact on treatment outcome in NSLBP patients who also show non-acute [48] depression, pain catastrophising, fear of pain and avoidance. These aspects are part of the fearavoidance model of chronic pain, and previous data has reported its various effects on treatment outcome [49]. Pain-related fear and subsequent avoidance of movements that patients believe to be harmful can also lead to disability and physical deconditioning [50]. In our study patients with a high risk of psychosocial problems are excluded based on an assessment with the Örebrö Musculoskeletal Pain Questionnaire (ÖMPQ) [51,52].
This influential variable will be observed using the Fearavoidance beliefs questionnaire.

This randomised controlled trial will, to our knowledge, be the first to compare two exercise programs for a well-defined subgroup of patients with non-specific low back pain and movement control impairment. We will evaluate the effect of individualised movement control exercise versus general exercise on disability during a one year follow-up period.

\section{Methods/Design \\ Design}

In this randomised controlled trial we will include patients with non-acute NSLBP and MCI. Patients will be recruited and treated in 5 hospital outpatient departments and 8 private practices in Switzerland. Movement control exercise will be compared to general exercise. Treatment outcomes are to be measured at baseline, post-treatment, and at 6 and 12 months follow-up (Figure 1).

Ethical approval has been granted by the Swiss Ethics Commission for Clinical Trials in the cantons of Zurich, Basel and Aargau (Switzerland). Reporting of the RCT will follow the recommendations of CONSORT Statement 2010 http://www.consort-statement.org [53].

\section{Hypotheses}

1. In NSLBP patients with MCI, treatment with movement control exercises will result in a significant decrease in disability compared to general

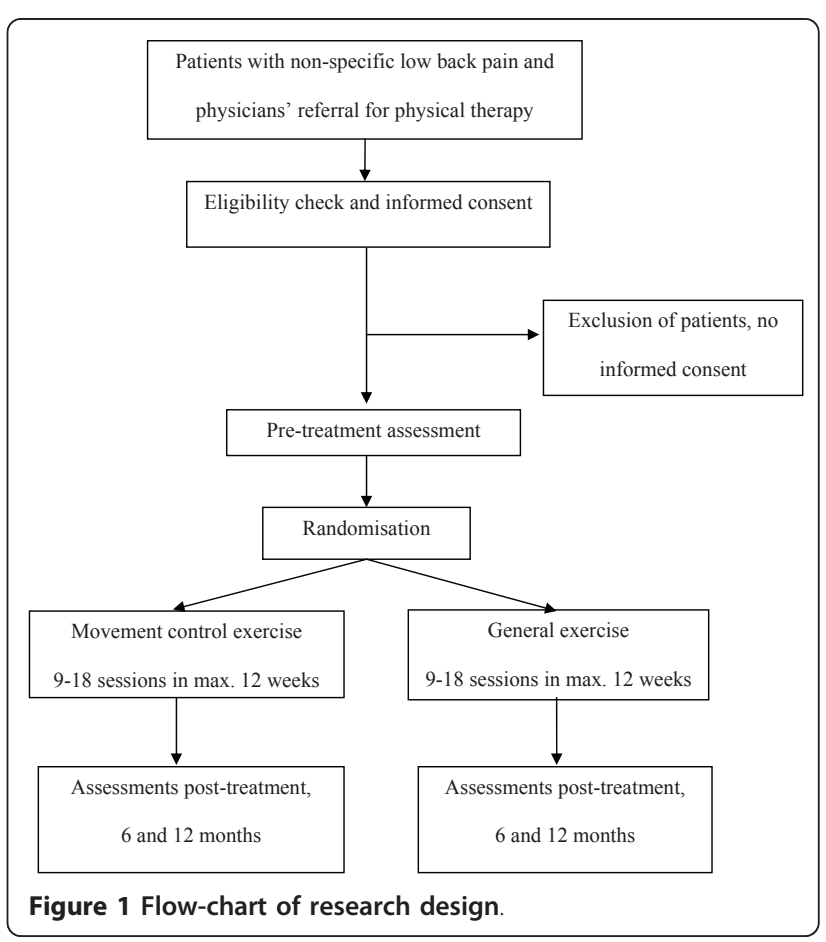


exercise, measured with the patient specific functional scale.

2. In NSLBP patients with MCI, improvement in motor control of the lumbar spine, assessed with standardised clinical tests, is associated with functional improvement and pain reduction.

\section{Participants and recruitment}

Admission criteria for the study are described in Table 2. Eligible are patients with NSLBP referred to physiotherapy by their physician. Patients will be recruited by the participating physiotherapists. Patients are included in the study if at least $2 \mathrm{MCI}$ tests are positive and if they present clinical symptoms of MCI as described by $[21,24,25,27,30,36]$. Patients with specific LBP, identified by the physician or by the physiotherapist are excluded from the study. To prevent floor effects in outcome measurement, a minimal disability of 5 points on the Roland and Morris Disability Questionnaire (RMQ) [54] is required. Excluded are patients with predominant psychosocial factors, defined as a score of more than 130 points on the Örebrö Musculoskeletal Pain Questionnaire (ÖMPQ) [51,52]. An ÖMPQ score of over 130 has been shown to correctly predict failure of return to work in $86 \%$ of cases [51]. The German version of the ÖMPQ has been used in a previous study in Switzerland [55].

\section{Baseline assessment and randomisation}

After eligibility has been confirmed, patients will be informed about the study comparing two treatments that are widely used in physiotherapy. After obtaining written informed consent, baseline measurements will be performed (see next paragraph). Participants will then be randomised using block allocation with a block size of four, to receive either movement control or general exercise. Randomisation is concealed and performed by an independent assistant at the School of Health Professions at the Zurich University of Applied Sciences via telephone.

\section{Outcome measurements}

Criteria for the selection of the outcome measurements are reliability, validity and sensitivity for statistical change.

\section{Primary outcome}

Patient-specific LBP-related disability will be assessed using the patient specific functional scale (PSFS), a selfreported measurement for up to three individual activity limitations rated on an 11-point numeric rating scale ranging 0-10 [56]. Measurement is taken at baseline, post-treatment, and at 6 and 12 months follow-up. Reliability and validity have been reported to be good $[57,58]$. Internal and external responsiveness are good, indicating that the test detects a change in active limitation and that this change is meaningful [59]. In patients with low levels of activity limitations, the PSFS has better responsiveness than the RMQ [60].

\section{Secondary outcomes}

General LBP-related disability will be assessed with the RMQ [54]. It consists of 24 dichotomous questions to be answered with yes or no, and has a maximum disability score of 24 points. Measurement is taken at baseline, post-treatment and at 6 and 12 months follow-up. Reliability and validity have been widely tested, reliability is high, and construct and internal validity are good [61]. The reliability and validity of the German version have been confirmed [48].

Pain, daily activities, social participation and professional participation will be assessed using the Graded Chronic Pain Scale (chronic pain grade $=$ CPG) [62]. The German version of the questionnaire shows significant correlations with other assessments of

Table 2 Inclusion and exclusion criteria

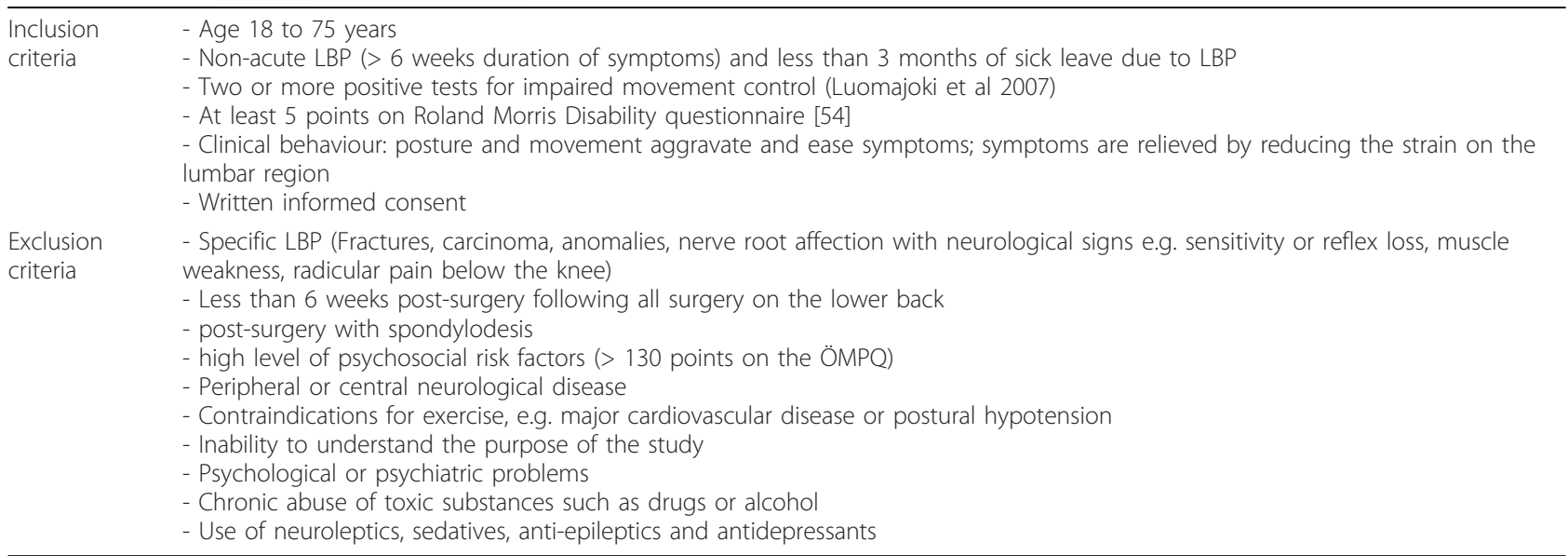


disability and staging of chronic pain, and a good internal consistency (Cronbach's alpha $=.82$ ) [63]. Measurement is taken at baseline, post-treatment, and at 6 and 12 months follow-up. Sports and leisure activities will be assessed with a self-administered questionnaire developed for this study.

Range of motion is measured pre- and post-treatment by finger to floor distance, a valid, reliable and responsive measurement correlating with radiography in patients with chronic low back pain [64].

Tactile acuity (two point discrimination TPD) is measured in the paravertebral lumbar region using a plastic caliper ruler between L1 and the iliac crest. Measurements are taken horizontally and vertically. The two point discrimination threshold is where the smallest distance at which the patient correctly reports feeling two points of the caliper instead of one is located. We will calculate the average of two procedures; one starting with an extended position of the calipers with the distance being decreased, the other starting with calipers in a contracted position and the distance being increased. Out of sequence tests are performed to avoid the recognition of a pattern. This test was recently used in patients with NSLBP [30]. Reliability was not formally evaluated in this population. TPD is measured pre- and post-treatment.

Direct and indirect LBP related costs will be calculated based on the use of medication and medical treatment. Data are recorded according to information given by the patient. Indirect costs are calculated in sick leave days costs based on Swiss average salary data (Statistisches Jahrbuch der Schweiz, 2011).

\section{Treatment effect modifiers}

The following relevant covariates will be recorded in order to allow them to be controlled for in the analysis of this study. Movement control and endurance are addressed in the two treatment groups and are expected to modify treatment effect.

Movement control impairment of the lumbar spine is assessed using 6 tests described in the backgrounds section [65]. Post-treatment the test will be recorded on videotape. The evaluation of video footage will be carried out by a specially trained physiotherapist who will be blinded to the treatment allocation and data from previous measurements.

Endurance of lumbar and abdominal muscles is assessed using static isometric strength tests for trunk extension and for trunk flexion pre- and post-treatment $[66,62]$.

Fear avoidance beliefs will be measured with the selfreport Fear-avoidance beliefs questionnaire for physical activities and work developed by Waddell et al $[67,68]$. The validated Swiss German Version will be used, allowing prediction of treatment outcome [67] It will be administered at baseline.

Patient's regular use of home exercises will be assessed at 6 and 12 months follow-up.

Personal characteristics (age, gender, previous episodes of back pain) will be collected at baseline.

\section{Interventions}

Assessors and treating physiotherapists in both groups are trained for at least 4 hours and receive a manual containing descriptions of procedures and checklists. To support adherence to the treatment procedures, a structured recording form is provided. This study uses a pragmatic approach to treatment progression in both intervention groups. The therapist responsible for treatment has to select from exercises permitted for the relevant treatment group. The exercise prescription for the individual patient is determined by the clinical judgement of the therapist. Patients in each group will be treated by their specially trained physiotherapists in individual 30 minute sessions. Patients will receive 9-18 treatments within a period of 12 weeks. The number of treatments will be recorded. At least 20 minutes of each session are to be used for exercise according to the protocol. If required, a maximum of 10 minutes can be used for other physical therapy applications. Therapy will be monitored and evaluated using a therapists' treatment diary.

Patients are instructed to do at least three home exercises of either movement control or general exercise. They are strongly encouraged to continue them during the follow-up year. Patients are informed about frequency, number of repetitions and the intensity at which they are to perform the exercises.

\section{Movement control exercise group}

The patients in the movement control group will receive exercise treatment aimed at improving movement control of the lumbar spine as described in previous publications $[21,34,69]$. Patient education addresses awareness of positive and negative postural and movement related behaviour and increasing selfefficacy. Exercises are selected based on the direction of the impairment i.e. flexion, extension or frontal plane. The first step for patients is to learn to control the position and movement of the lumbar spine in different postures such as standing, squatting, 4 point kneeling and sitting. Movement control is practiced in combination with upper and lower extremity movements. In a second step, the difficulty level of exercise is increased through additional loading using long leavers or weights. If necessary, stretching/lengthening is applied after movement control has improved. Sports and strength training are allowed once good movement control is achieved. 


\section{General exercise group}

Patients in this group are to be treated with the aim of improving endurance, strength and flexibility of the lumbar region. Patient education will address the importance of exercise and strength to reduce LBP. Exercises will address abdominals, erector spinae, gluteal, quadriceps and hamstrings muscle groups. The standardised exercise program starts in non-weight bearing positions and can be progressed by increasing load. Weights and resistance will be individually and progressively increased according to the guidelines of the American College of Sports Medicine [70]. The use of equipment is not standardised and will be left to the discretion of the therapists.

\section{Main treatment contrast}

The main difference between the two treatments is the instruction of movement control in the MCI group, which will not be applied in the general exercise group.

\section{Sample size calculation}

Based on the results of our previous case series, intergroup difference in improvement of 0.9 points on the PSFS is to be used [71]. This difference is also clinically relevant as it displays an improvement of approximately $20 \%$ compared with an expected PSFS baseline score of 5 points. We used a standard deviation of 1.5 points, alpha was set at 0.05 and the power was set at 0.9. In each group, 48 patients are needed. Anticipating a 10\% drop-out rate, the required sample size was set at 106 patients to be randomised.

\section{Data analysis}

The comparability of both groups on prognostic and outcome variables at baseline will be analysed using two-sample t-tests in data with a normal distribution, Wilcoxon tests in non-parametric data and Chi-square tests in nominal data. An intention-to-treat analysis will be utilised in which all participants will be analysed in the group to which they were originally assigned. Differences between the groups over time are measured by Mann-Whitney-U-test. The influence of baseline differences on outcome measurements will be assessed in a multivariable linear regression analysis. A regression analysis of the factors being positive or negative predictors will be conducted based on covariates measured at baseline. Statistical significance is set at $\mathrm{p}<0.05$.

\section{Blinding}

Patients and therapists cannot be blinded to treatment. To keep patients unaware of any expected treatment group benefit, patients will be informed that the effect of two well-established therapies is to be evaluated. An independent and blinded assessor will record videos of the movement control tests at the end of the treatment phase and perform the post-treatment physical examination. A second blinded assessor will rate the video recordings of the MCI tests. Statistical analysis will be blinded regarding treatment group code. The researcher who will perform the statistical analyses will not be involved in taking the measurements.

\section{Results}

Inclusion of patients began in July 2010 and is expected to last until the end of 2011. Results are expected in 2013.

\section{Discussion}

This randomised controlled trial will compare the effectiveness of two exercise-based physiotherapy treatment protocols in a well-defined subgroup of NSLP. Inclusion is based on the clinical diagnosis of MCI with clinical tests shown to be reliable. The MCI tests allow easily applicable selection of participants. We will evaluate whether a treatment protocol addressing movement control problems is more beneficial than a general exercise protocol.

The multicentre design of the study allows treatment by different physiotherapists and improves generalisability. The selection of patients reflects the population usually found in different clinical settings. Randomisation is organised centrally and prevents selection bias.

Both treatment protocols are widely used and wellestablished in physiotherapy. The physiotherapists treating each group are equally instructed and experienced in applying the respective treatments. This prevents a disadvantage for the participating patients regarding group allocation.

Blinding the therapists is generally not possible. To minimise measurement bias, the measurements taken after the treatment will be taken by an assessor not involved in the treatment procedures.

The results of this study will provide evidence to improve the selection of exercise treatments for patients with NSLBP and MCI. Results will also contribute to the understanding of the mechanisms behind MCI and its relation to low back pain.

\section{Additional material}

Additional file 1: Assessments for movement control. Six tests which are instructed twice and demonstrated the third time. If two out of six tests are not correctly performed a movement control impairment can be diagnosed.

\section{Abbreviations}

CPG: Chronic pain grade; GCPS: Graded chronic pain scale; MCl: Movement control impairment; MI: Movement impairment; NSLBP: Non-specific low back pain; ÖMPQ: Örebrö musculoskeletal pain questionnaire; PSFS: Patient 
specific functional scale; RCT: Randomised controlled trial; RMQ: Roland Morris disability questionnaire; TPD: Two point discrimination

\section{Acknowledgements}

The authors would like to acknowledge the main input of the physiotherapists and doctors in clinics and practices in Switzerland, which are: Bethesda Spital, Basel; Kantonsspital Winterthur, Winterthur; Klinik Schulthess, Zurich; Medbase Physiotherapie, Winterthur; Physiotherapie Seen, Winterthur; Physiotherapie Bellaria, Zurich; Physiotherapie Erlenbach, Erlenbach; Physiotherapie Reinach, Reinach; Physiotherapie Würenlingen, Würenlingen; Provital Physiotherapie, Egg; Rheumaklinik, Universitätsspital Zurich, Zurich; Segeten Physiotherapie, Zurich; Uniklinik Balgrist, Zurich. We'd like to express our gratitude to Dr. med. Andreas Klipstein and Dr. med. Michael Gengenbacher for their contribution in getting ethical approval.

Further we would like to acknowledge Caroline HG Bastiaenen for her input to the research design, and Daryl Snell for his assistance in preparing the final manuscript.

The project was supported by Swiss National Science Foundation (SNSF). (Project no. 127240) HL, JK, JS are funded by SNSF; JMS and RAB are funded by CAPHRI School for Public Health and Primary Care, Maastricht University.

\section{Author details}

${ }^{1}$ Institute of Physiotherapy, School of Health Professions, Zurich University of Applied Sciences, Technikumstrasse 71, Postfach, CH - 8401 Winterthur, Switzerland. ${ }^{2}$ Dept. of Methodology and Statistics, CAPHRI School of Public Health and Primary Care, Maastricht University, Maastricht, The Netherlands. ${ }^{3}$ Department of Anatomy \& Embryology, Maastricht University, Maastricht, The Netherlands.

\section{Authors' contributions}

HL originated the idea of the study, which is based on his previous work. $\mathrm{HL}, J K$, JS, JMS designed the trial protocol. JS drafted the manuscript and the other authors revised it critically, corrected draft versions and approved the final manuscript.

\section{Competing interests}

The authors declare that they have no competing interests.

Received: 14 July 2011 Accepted: 23 September 2011

Published: 23 September 2011

\section{References}

1. Airaksinen O, Brox J, Cedraschi C, Hildebrandt J, Klaber-Moffett J, Kovacs F, Mannion A, Reis S, Staal J, Ursin H, Zanoli G: Chapter 4. European guidelines for the management of chronic nonspecific low back pain. Eur Spine J 2006, 15(Suppl 2):S192-300.

2. van Tulder M, Becker A, Bekkering T, Breen A, del Real MT, Hutchinson A, Koes B, Laerum E, Malmivaara A: Chapter 3. European guidelines for the management of acute nonspecific low back pain in primary care. Eur Spine J 2006, 15(Suppl 2):S169-191.

3. Dionne $C E$, Dunn KM, Croft PR, Nachemson AL, Buchbinder R, Walker BF, Wyatt M, Cassidy JD, Rossignol M, Leboeuf-Yde C, et al: A consensus approach toward the standardization of back pain definitions for use in prevalence studies. Spine (Phila Pa 1976) 2008, 33:95-103.

4. Chou R, Loeser JD, Owens DK, Rosenquist RW, Atlas SJ, Baisden J, Carragee EJ, Grabois M, Murphy DR, Resnick DK, et al: Interventional therapies, surgery, and interdisciplinary rehabilitation for low back pain: an evidence-based clinical practice guideline from the American Pain Society. Spine (Phila Pa 1976) 2009, 34:1066-1077.

5. Dagenais S, Tricco AC, Haldeman S: Synthesis of recommendations for the assessment and management of low back pain from recent clinical practice guidelines. Spine J 2010, 10:514-529.

6. Koes BW, van Tulder MW, Thomas S: Diagnosis and treatment of low back pain. BMJ 2006, 332:1430-1434.

7. Borkan J, Van Tulder M, Reis S, Schoene ML, Croft P, Hermoni D: Advances in the field of low back pain in primary care: a report from the fourth international forum. Spine (Phila Pa 1976) 2002, 27:E128-132.

8. Bouter $L$, van Tulder $M$, Koes $B$ : Methodologic issues in low back pain research in primary care. Spine (Phila Pa 1976) 1998, 23:2014-2020.
9. Donelson R: Evidence-based low back pain classification. Improving care at its foundation. Eura Medicophys 2004, 40:37-44.

10. Billis $E, M c C a r t h y ~ C$, Oldham J: Subclassification of low back pain: a crosscountry comparison. Eur Spine J 2007, 16:865-879.

11. O'Sullivan P: Diagnosis and classification of chronic low back pain disorders: Maladaptive movement and motor control impairments as underlying mechanism. Manual Therapy 2005, 10:242-255.

12. Brennan GP, Fritz JM, Hunter SJ, Thackeray A, Delitto A, Erhard RE: Identifying subgroups of patients with acute/subacute "nonspecific" low back pain: results of a randomized clinical trial. Spine (Phila Pa 1976) 2006, 31:623-631.

13. Kent $P$, Keating $J$, Leboeuf-Yde $C$ : Research methods for subgrouping low back pain. BMC Med Res Methodol 2010, 10:62.

14. Fersum KV, Dankaerts W, O'Sullivan PB, Maes J, Skouen JS, Bjordal JM, Kvale A: Integration of sub-classification strategies in RCTs evaluating manual therapy treatment and exercise therapy for non-specific chronic low back pain (NSCLBP): a systematic review. Br J Sports Med 2009.

15. Hayden JA, van Tulder MW, Malmivaara A, Koes BW: Exercise therapy for treatment of non-specific low back pain. Cochrane Database Syst Rev 2005, CD000335.

16. Hayden JA, van Tulder MW, Malmivaara AV, Koes BW: Meta-analysis: exercise therapy for nonspecific low back pain. Ann Intern Med 2005, 142:765-775.

17. Hayden JA, van Tulder MW, Tomlinson G: Systematic review: strategies for using exercise therapy to improve outcomes in chronic low back pain. Ann Intern Med 2005, 142:776-785.

18. Oesch P, Kool J, Hagen KB, Bachmann S: Effectiveness of exercise on work disability in patients with non-acute non-specific low back pain: Systematic review and meta-analysis of randomised controlled trials. J Rehabil Med 2010, 42:193-205.

19. Choi B, K L, Verbeek Jos H, Tam Wilson W-S, Jiang Johnny Y: Exercises for prevention of recurrences of low-back pain. Book Exercises for prevention of recurrences of low-back pain City: John Wiley \& Sons, Ltd; 2010.

20. Dankaerts W, O'Sullivan P, Burnett A, Straker L, Davey P, Gupta R. Discriminating healthy controls and two clinical subgroups of nonspecific chronic low back pain patients using trunk muscle activation and lumbosacral kinematics of postures and movements: a statistical classification model. Spine (Phila Pa 1976) 2009, 34:1610-1618.

21. O'Sullivan PB: Masterclass. Lumbar segmental 'instability': clinical presentation and specific stabilizing exercise management. Manual Therapy 2000, 5:2-12.

22. Vibe Fersum K, O'Sullivan PB, Kvale A, Skouen JS: Inter-examiner reliability of a classification system for patients with non-specific low back pain. Man Ther 2009, 14:555-561.

23. Van Dillen LR, Sahrmann SA, Norton BJ, Caldwell CA, McDonnell MK Bloom NJ: Movement system impairment-based categories for low back pain: stage 1 validation. The Journal of orthopaedic and sports physical therapy 2003, 33:126-142.

24. Sahrmann SA: Diagnosis and treatment of movement impairment syndromes St. Louis: Mosby; 2002.

25. Comerford MJ, Mottram SL: Functional stability re-training: principles and strategies for managing mechanical dysfunction. Manual Therapy 2001, 6:3-14.

26. Comerford MJ, Mottram SL: Movement and stability dysfunction contemporary developments. Manual Therapy 2001, 6:15-26.

27. Luomajoki $\mathrm{H}$, Kool J, de Bruin ED, Airaksinen O: Reliability of movement control tests in the lumbar spine. BMC Musculoskelet Disord 2007, 8:90.

28. Moseley GL: I can't find it! Distorted body image and tactile dysfunction in patients with chronic back pain. Pain 2008, 140:239-243.

29. Flor H, Diers M: Sensorimotor training and cortical reorganization. NeuroRehabilitation 2009, 25:19-27.

30. Luomajoki H, Moseley GL: Tactile acuity and lumbopelvic motor control in patients with back pain and healthy controls. Br J Sports Med 2009.

31. Solomonow M, Baratta RV, Banks A, Freudenberger C, Zhou BH: Flexionrelaxation response to static lumbar flexion in males and females. Clin Biomech (Bristol, Avon) 2003, 18:273-279.

32. Solomonow M, Eversull E, He Zhou B, Baratta RV, Zhu MP: Neuromuscular neutral zones associated with viscoelastic hysteresis during cyclic lumbar flexion. Spine (Phila Pa 1976) 2001, 26:E314-324. 
33. Mense S: Pathophysiology of low back pain and the transition to the chronic state - experimental data and new concepts. Schmerz 2001, 15:413-417.

34. Dankaerts W, O'Sullivan P, Burnett A, Straker L: Differences in sitting postures are associated with nonspecific chronic low back pain disorders when patients are subclassified. Spine (Phila Pa 1976) 2006, 31:698-704.

35. Dankaerts W, O'Sullivan PB, Straker LM, Burnett AF, Skouen JS: The interexaminer reliability of a classification method for non-specific chronic low back pain patients with motor control impairment. Manual Therapy 2006, 11:28-39.

36. Luomajoki $\mathrm{H}$, Kool J, de Bruin ED, Airaksinen O: Movement control tests of the low back; evaluation of the difference between patients with low back pain and healthy controls. BMC Musculoskelet Disord 2008, 9:170.

37. Luomajoki H: Movement control impairment as an output of distorted body image. Book Movement control impairment as an output of distorted body image City; 2010.

38. Macedo LG, Maher CG, Latimer J, McAuley JH: Motor control exercise for persistent, nonspecific low back pain: a systematic review. Phys Ther 2009, 89:9-25.

39. Rasmussen-Barr E, Nilsson-Wikmar L, Arvidsson I: Stabilizing training compared with manual treatment in sub-acute and chronic low-back pain. Man Ther 2003, 8:233-241.

40. Shaughnessy M, Caulfield B: A pilot study to investigate the effect of lumbar stabilisation exercise training on functional ability and quality of life in patients with chronic low back pain. Int J Rehabil Res 2004, 27:297-301.

41. May S: Stabilisation exercises for low back pain: a systematic review. Physiotherapy 2008, 94:179-189

42. Ferreira P, Ferreira M, Maher C, Herbert R, Refshauge K: Specific stabilisation exercise for spinal and pelvic pain: a systematic review. Aust J Physiother 2006, 52:79-88.

43. Costa L, Maher C, Latimer J, Hodges P, Herbert R, Refshauge K, McAuley J, Jennings M: Motor control exercise for chronic low back pain: a randomized placebo-controlled trial. Phys Ther 2009, 89:1275-1286.

44. McGill SM: Low back exercises: evidence for improving exercise regimens. Phys Ther 1998, 78:754-765.

45. Kavcic N, Grenier S, McGill SM: Quantifying tissue loads and spine stability while performing commonly prescribed low back stabilization exercises. Spine (Phila Pa 1976) 2004, 29:2319-2329.

46. Kavcic N, Grenier S, McGill SM: Determining the stabilizing role of individual torso muscles during rehabilitation exercises. Spine (Phila Pa 1976) 2004, 29:1254-1265

47. Koumantakis GA, Watson PJ, Oldham JA: Trunk muscle stabilization training plus general exercise versus general exercise only: randomized controlled trial of patients with recurrent low back pain. Phys Ther 2005, 85:209-225.

48. Wiesinger GF, Nuhr M, Quittan M, Ebenbichler G, Wolfl G, Fialka-Moser V: Cross-cultural adaptation of the Roland-Morris questionnaire for German-speaking patients with low back pain. Spine (Phila Pa 1976) 1999, 24:1099-1103.

49. Leeuw M, Goossens ME, Linton SJ, Crombez G, Boersma K, Vlaeyen JW: The fear-avoidance model of musculoskeletal pain: current state of scientific evidence. J Behav Med 2007, 30:77-94.

50. Sieben JM, Vlaeyen JW, Portegijs PJ, Verbunt JA, van Riet-Rutgers $\mathrm{S}$, Kester AD, Von Korff M, Arntz A, Knottnerus JA: A longitudinal study on the predictive validity of the fear-avoidance model in low back pain. Pain 2005, 117:162-170

51. Linton SJ, Boersma K: Early identification of patients at risk of developing a persistent back problem: the predictive validity of the Orebro Musculoskeletal Pain Questionnaire. Clin J Pain 2003, 19:80-86

52. Linton SJ, Hallden K: Can we screen for problematic back pain? A screening questionnaire for predicting outcome in acute and subacute back pain. Clinical Journal of Pain 1998, 14:209-215.

53. Moher D, Hopewell S, Schulz KF, Montori V, Gotzsche PC, Devereaux PJ, Elbourne D, Egger M, Altman DG: CONSORT 2010 Explanation and Elaboration: updated guidelines for reporting parallel group randomised trials. Brit Med J 2010, 340:-

54. Roland M, Morris R: A study of the natural history of back pain. Part I: development of a reliable and sensitive measure of disability in lowback pain. Spine 1983, 8:141-144.
55. Tamcan O: Bewältigungsressourcen bei Rückenschmerzen: ein neues erhebungsinstrument für die therapeutische Praxis. Z Med Psychol 2010, 19:21-29.

56. Pengel LH, Refshauge KM, Maher CG: Responsiveness of pain, disability, and physical impairment outcomes in patients with low back pain. Spine (Phila Pa 1976) 2004, 29:879-883.

57. Stratford PGC, Westaway M, Binkley J: Assessing disability and change on individual patients: a report of a patient specific measure. Physiother Canada 1995, 47:258-263.

58. Cleland JA, Fritz JM, Whitman JM, Palmer JA: The reliability and construct validity of the Neck Disability Index and patient specific functional scale in patients with cervical radiculopathy. Spine (Phila Pa 1976) 2006, 31:598-602.

59. Beurskens AJ, de Vet HC, Koke AJ, Lindeman E, van der Heijden GJ, Regtop W, Knipschild PG: A patient-specific approach for measuring functional status in low back pain. J Manipulative Physiol Ther 1999, 22:144-148,

60. Hall AM, Maher CG, Latimer J, Ferreira ML, Costa LO: The patient-specific functional scale is more responsive than the Roland Morris disability questionnaire when activity limitation is low. Eur Spine J 2010.

61. Roland M, Fairbank J: The Roland-Morris Disability Questionnaire and the Oswestry Disability Questionnaire. Spine (Phila Pa 1976) 2000, 25:3115-3124.

62. Latimer J, Maher CG, Refshauge K, Colaco I: The reliability and validity of the Biering-Sorensen test in asymptomatic subjects and subjects reporting current or previous nonspecific low back pain. Spine (Phila Pa 1976) 1999, 24:2085-2089, discussion 2090

63. Klasen BW, Hallner D, Schaub C, Willburger R, Hasenbring M: Validation and reliability of the German version of the Chronic Pain Grade questionnaire in primary care back pain patients. Psychosoc Med 2004, 1: Doc07.

64. Perret C, Poiraudeau S, Fermanian J, Colau MM, Benhamou MA, Revel M: Validity, reliability, and responsiveness of the fingertip-to-floor test. Arch Phys Med Rehabil 2001, 82:1566-1570.

65. Luomajoki H, Kool J, de Bruin E, Airaksinen O: Reliability of movement control tests in the lumbar spine. BMC Musculoskelet Disord 2007, 8:90.

66. Biering-Sorensen F: Physical measurements as risk indicators for low-back trouble over a one-year period. Spine (Phila Pa 1976) 1984, 9:106-119.

67. Staerkle R, Mannion AF, Elfering A, Junge A, Semmer NK, Jacobshagen N, Grob D, Dvorak J, Boos N: Longitudinal validation of the fear-avoidance beliefs questionnaire (FABQ) in a Swiss-German sample of low back pain patients. Eur Spine J 2004, 13:332-340.

68. Waddell G, Newton M, Henderson I, Somerville D, Main CJ: A FearAvoidance Beliefs Questionnaire (FABQ) and the role of fear-avoidance beliefs in chronic low back pain and disability. Pain 1993, 52:157-168.

69. Luomajoki H: Movement Control Impairment as a subgroup of nonspecific low back pain. Book Movement Control Impairment as a subgroup of non-specific low back pain City: Eastern Finland University Library/Sales of Publications; 2010, 70, 22.10.2010.

70. Whaley MH, (Ed.): ACSM's Guidelines for exercise testing and prescription Lippincott Williams \&Wilkins; 2006.

71. Luomajoki H, Kool J, de Bruin ED, Airaksinen O: Improvement in low back movement control, decreased pain and disability, resulting from specific exercise intervention. Sports Med Arthrosc Rehabil Ther Technol 2010, 2:11.

72. O'Sullivan PB, (Ed.): Clinical instability of the lumbar spine: its pathological basis, diagnosis, and conservative management. Amsterdam, The Netherlands: Elsevier; 32004

\section{Pre-publication history}

The pre-publication history for this paper can be accessed here: http://www.biomedcentral.com/1471-2474/12/207/prepub

\section{doi:10.1186/1471-2474-12-207}

Cite this article as: Saner et al:: Movement control exercise versus general exercise to reduce disability in patients with low back pain and movement control impairment. A randomised controlled trial. BMC Musculoskeletal Disorders 2011 12:207. 